\title{
The semianalytical cloud retrieval algorithm for SCIAMACHY II. The application to MERIS and SCIAMACHY data
}

\author{
A. A. Kokhanovsky, W. von Hoyningen-Huene, V. V. Rozanov, S. Noël, K. Gerilowski, H. Bovensmann, K. Bramstedt, \\ M. Buchwitz, and J. P. Burrows \\ Institute of Remote Sensing, University of Bremen, Germany
}

Received: 15 April 2004 - Published in Atmos. Chem. Phys. Discuss.: 13 March 2006

Revised: 1 June 2006 - Accepted: 13 September 2006 - Published: 18 September 2006

\begin{abstract}
The SemiAnalytical CloUd Retrieval Algorithm (SACURA) is applied to the SCanning Imaging Absorption spectroMeter for Atmospheric CHartographY (SCIAMACHY) data. In particular, we derive simultaneously cloud optical thickness (COT) and cloud top height (CTH), using SCIAMACHY measurements in the visible $(442 \mathrm{~nm}, \mathrm{COT})$ and in the oxygen A-band (755-775 $\mathrm{nm}, \mathrm{CTH})$. Some of the results obtained are compared with those derived from the Medium Resolution Imaging Spectrometer (MERIS), which has better spatial resolution and observes almost the same scene as SCIAMACHY. The same cloud algorithm is applied to both MERIS and SCIAMACHY data. In addition, we perform the vicarious calibration of SCIAMACHY at the wavelength $442 \mathrm{~nm}$, using MERIS measurements at the same wavelength. Differences in the retrieved COT for the same cloud field obtained using MERIS and SCIAMACHY measurements are discussed.
\end{abstract}

\section{Introduction}

In addition to being one of the most significant components of the hydrological cycle, clouds scatter and absorb electromagnetic radiation in the atmosphere. Their amount and distribution are of a great significance for radiative transfer and the atmospheric radiative balance. Clouds have a direct role in climate and global climate change. There are several important issues in the cloud research area (for example, the coupling of gases and clouds via gas-aerosol-cloud interactions and the ability of clouds to precipitate; see Crutzen and Ramanathan, 1996; Raschke, 1996). For both climate research and numerical weather prediction, it is necessary to have knowledge about cloud parameters on a global scale.

Correspondence to: A. Kokhanovsky

(alexk@iup.physik.uni-bremen.de)
This is only feasible from spaceborne remote sensing instrumentation.

A variety of techniques have been developed for the remote sensing of clouds. They are mostly based on the lookup-table approach (LUT). Then spectral reflectances are calculated for multiple illumination and observation conditions and stored in special tables. Subsequently, the measured spectral reflectances are compared with pre-calculated values in an iterative manner until the minimum deviation is found. It is believed that cloud parameters found for this minimum represent characteristics of a cloud field under study.

The SemiAnalytical CloUd Retrieval Algorithm (SACURA), used in this study, does not rely on LUTs at all. Instead we use semianalytical solutions of the radiative transfer equation valid for weakly absorbing clouds having large optical thickness (Kokhanovsky et al., 2003; Kokhanovsky and Rozanov, 2003, 2004; Rozanov and Kokhanovsky, 2004). This algorithm is fast, flexible and is readily applied to the data from different instruments. The effecive radius of droplets and the liquid water path are retrieved from measurements at the wavelengths 442 and $1550 \mathrm{~nm}$. This also enables the determination of the cloud optical thickness and the cloud spherical albedo. The cloud top height is determined fitting the SCIAMACHY measurements in oxygen A-band to the theoretical model as described in detail by Rozanov and Kokhanovsky (2004).

The manuscript describes the application of the algorithm to the data obtained from the SCanning Imaging Absorption spectroMeter for Atmospheric CHartographY (SCIAMACHY) on board of the ENVIronmental SATellite (ENVISAT). Technical characteristics of the SCIAMACHY are reported in Bovensmann et al. $(1999,2004)$ and references therein. Details of the SACURA are described elsewhere by Kokhanovsky et al. (2003) and Rozanov and Kokhanovsky (2004). The validation of SACURA is presented in a separate publication (Kokhanovsky et al., 2006). 


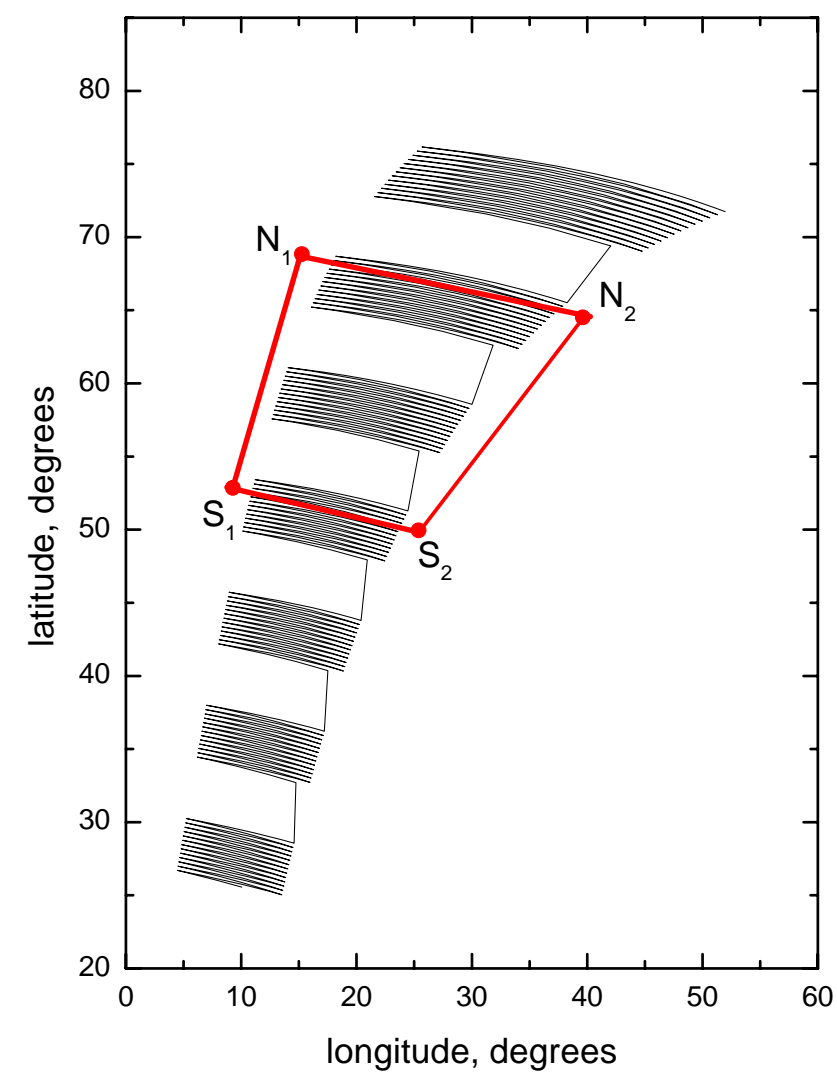

Fig. 1. The geographical position of the MERIS (red quadrangle) and SCIAMACHY (black lines) ground scenes analysed for the orbit 02223 (3 August 2002).

The following cloud parameters from SCIAMACHY measurements are retrieved by SACURA: the cloud optical thickness, the cloud droplet radius, the liquid water content, the cloud thermodynamic state and the cloud top height. The determination of such a long list of parameters is possible due to the broad spectral range, i.e. simultaneous measurements from 220 till $2380 \mathrm{~nm}$, coupled with high spectral resolution of this advanced optical instrument.

However, the spatial resolution of SCIAMACHY is limited as it requires a high signal to noise ratio to retrieve its primary objective, trace gas abundances. The spatial resolution is variable from $30 \times 240 \mathrm{~km}^{2}$ to $30 \times 60 \mathrm{~km}^{2}$. Extended cloud fields cover many millions of square kilometers and for such cloud systems the use of SCIAMACHY measurements for monitoring cloud properties is justified. Similarly the synergistic combination of SCIAMACHY data and the simultaneous high spatial resolution data of other optical instruments on ENVISAT for clouds having dimensions smaller than the ground scene of SCIAMACHY is of a great interest.

The main emphasis of Sect. 2 of this study is on the investigation of the cloud optical thickness (COT) as retrieved by SCIAMACHY at the wavelength $442 \mathrm{~nm}$. The retrievals are compared with those obtained from the Medium Resolution

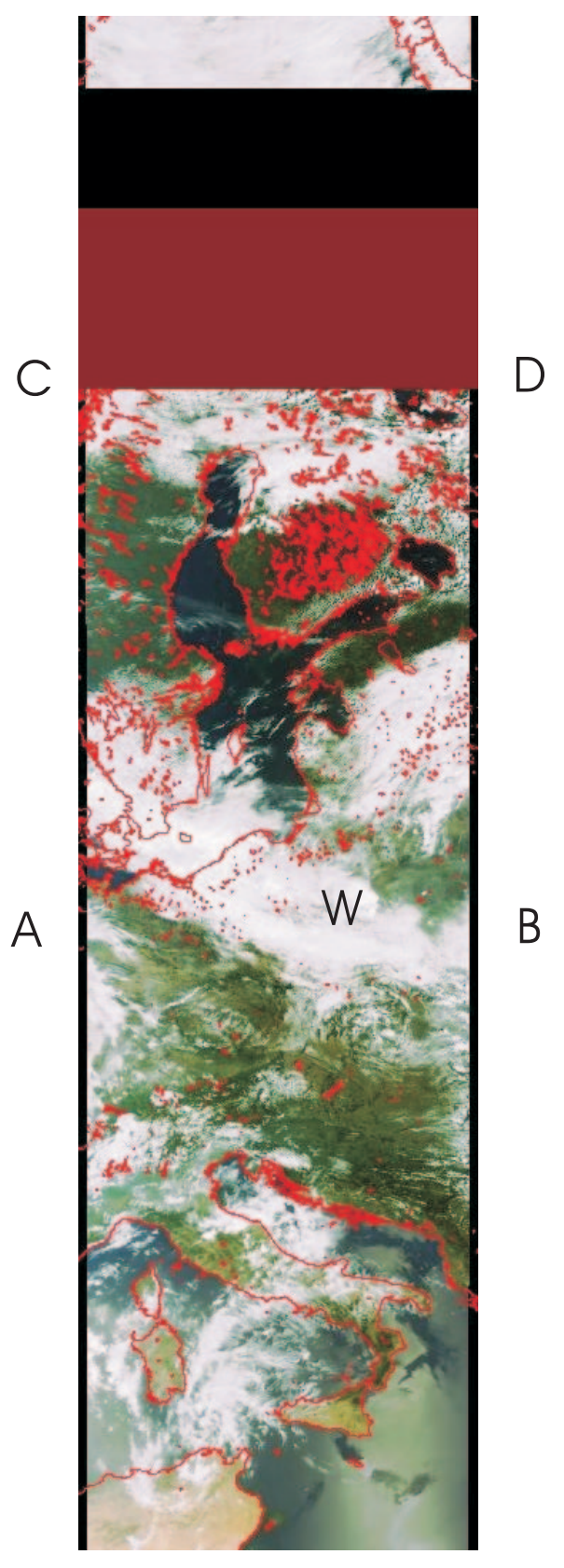

Fig. 2. The MERIS browse image for the same date and orbit as in Fig. 1.

Imaging Spectrometer (MERIS), whose measurements have significantly superior spatial resolution $\left(0.3 \times 0.3 \mathrm{~km}^{2}\right.$ or $1.1 \times 1.1 \mathrm{~km}^{2}$, dependent on the measurement mode). Thereafter Sect. 3 is devoted to the determination of the cloud thermodynamic state using the measurements of SCIAMACHY at wavelengths 1500 and $1670 \mathrm{~nm}$. The cloud phase index (CPI), which is defined to be the ratio of reflectances at these two wavelengths is introduced. We show that this ratio is sensitive to the cloud thermodynamic state. The cloud altitude 


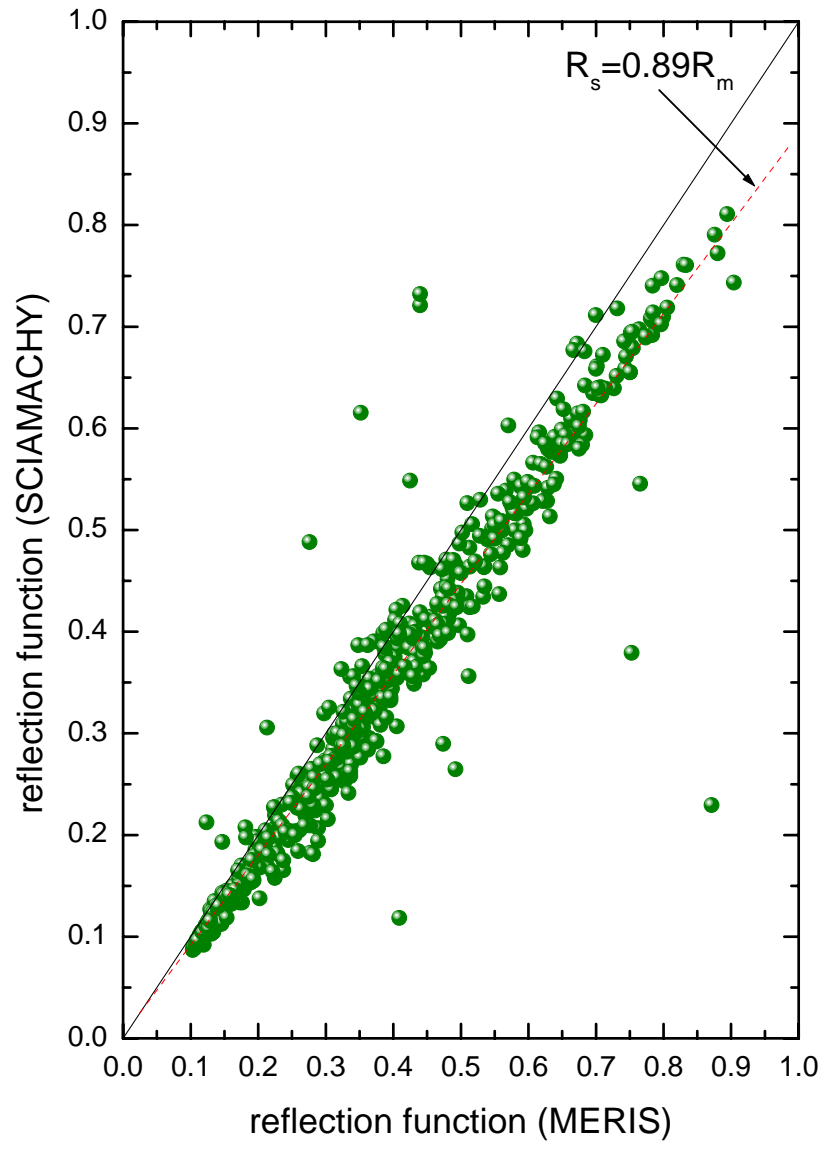

Fig. 3. Scatter plot of the SCIAMACHY reflectance versus that of MERIS at the wavelength $442 \mathrm{~nm}$.

determination using measurements in the oxygen A-band are explained and discussed in Sect. 4.

\section{The cloud optical thickness}

The geographical location of seven studied SCIAMACHY measurement states from the orbit 02223 (08:57, 3 August 2002) is shown in Fig. 1. Retrievals using MERIS data are performed in the quadrangle. The MERIS browse image of the area at the moment of measurements is shown in Fig. 2. The region above the line $A B$ roughly corresponds to that of a MERIS scene in Fig. 1. The letter $W$ in Fig. 2 shows the position of Warsaw. The MERIS browse image indicates that many clouds present in the scene. In particular, note an extended cloud area covering parts of Sweden, Poland, and Belarus. We found comparing our results with more extensive studies (in terms of spatial coverage) of Acarreta and Stammes (2005) that states investigated give statistically significant results.

The cloud reflection function as measured by SCIAMACHY versus the same function but obtained by the MERIS at the wavelength $442 \mathrm{~nm}$, where the contribu-

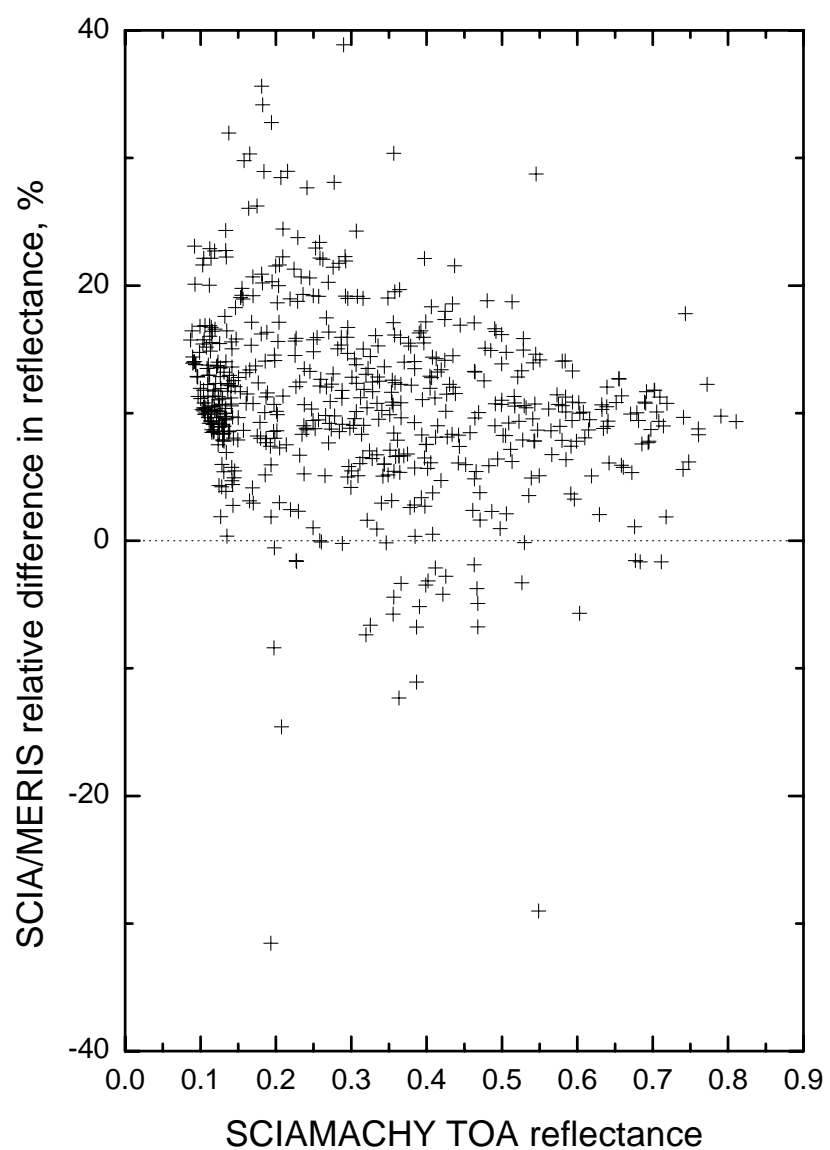

Fig. 4. The relative difference of the SCIAMACHY reflectance and that of MERIS (in percent) at the wavelength $442 \mathrm{~nm}$.

tion from the surface is relatively low is shown in Fig. 3. The definition of the reflection function is given, e.g., by Kokhanovsky et al. (2003).

The MERIS reflectances were averaged over large SCIAMACHY pixels and SCIAMACHY spectral reflectances were averaged taking into account the MERIS instrument response function. Both reflectances are highly correlated but they are not equal. On average, SCIAMACHY reflectances are a factor of 0.89 smaller than those obtained by the averaging of MERIS pixels at the wavelength $442 \mathrm{~nm}$.

If MERIS data are considered to be well calibrated, then the factor $C=1.12$ should be applied to SCIAMACHY data at $442 \mathrm{~nm}$ for correct retrievals of cloud parameters using absolute radiances. This is a major conclusion of this work. Note that von Hoyningen-Huene et al. (2006) find the same factor but analysing only carefully selected clear SCIAMACHY pixels over water. Acarreta and Stammes (2005) have obtained the same calibration constant at the wavelength $442 \mathrm{~nm}$, using much larger dataset with different underlying surfaces and solar illumination angles.

We present relative differences of both reflectances (in percent) in Fig. 4. It follows from this figure that SCIAMACHY 


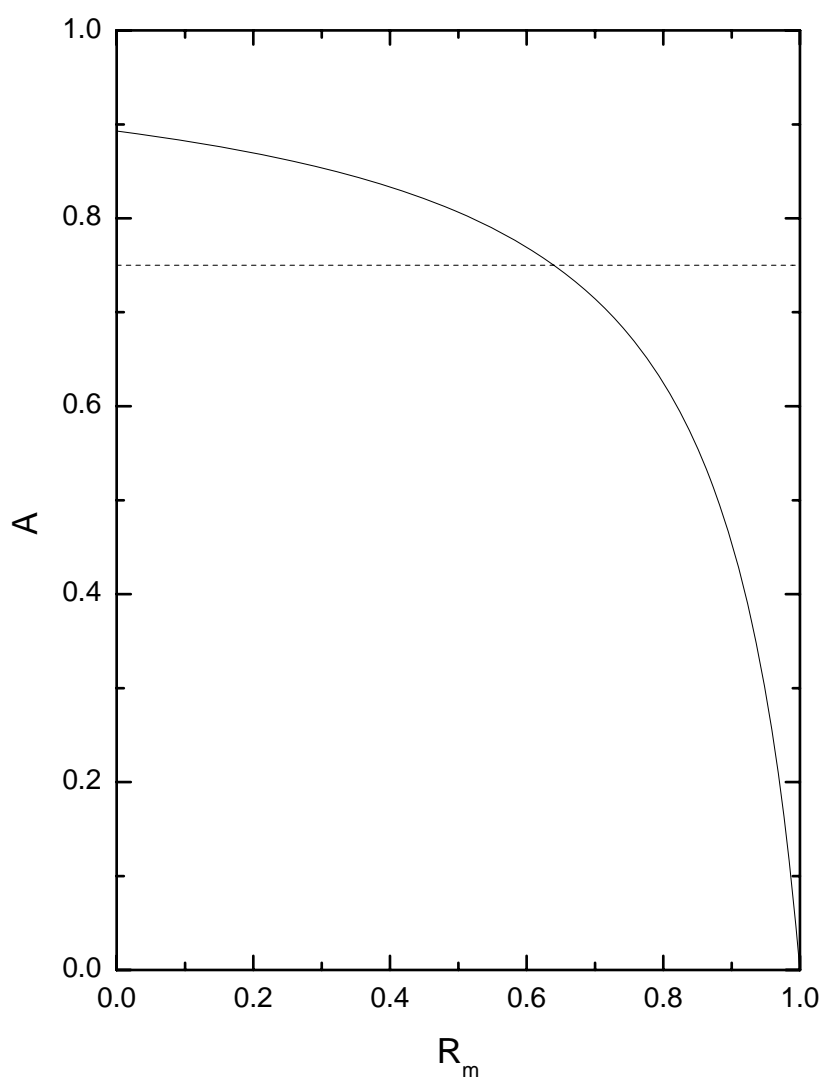

Fig. 5. The dependence of the parameter A (see Eq. 3) on the reflection function (the solid line). The broken line gives the average value of $\mathrm{A}$ equal to 0.75 .

reflectances are in the average 10 percent smaller than that of MERIS at the wavelength $442 \mathrm{~nm}$. However, values between 0 and $20 \%$ also occur. The dispersion of data around its average value of 10 percent is due to the problem with the instruments, atmospheric effects or both. Similar results were found comparing Advanced Along Track Scanning Spectrometer (AATSR) data with that of SCIAMACHY (B. Kerridge and $\mathrm{B}$. Latter, personal communication). So, clearly, SCIAMACHY Level1 data should be further improved with respect to the calibration correction.

Let us estimate what could be the result of the influence of the calibration error $\epsilon=12 \%$ (see above) on the retrieval of the cloud optical thickness. For this we will use a simple relationship between the COT $\tau$ and the reflection function $R$ for a cloud above a black surface given by Kokhanovsky et al. (2003):

$\tau=\frac{D K(\mu) K\left(\mu_{0}\right)}{R_{\infty}-R}-D b$,

where $D=\frac{4}{3(1-g)}, b=1.072$. Here the value of $g$ is the asymmetry parameter, $R_{\infty}$ is the reflection function of a semiinfinite cloud, $K(\mu)$ is the escape function, $\mu$ and $\mu_{0}$ are cosines of the observation and incidence angles, respectively.

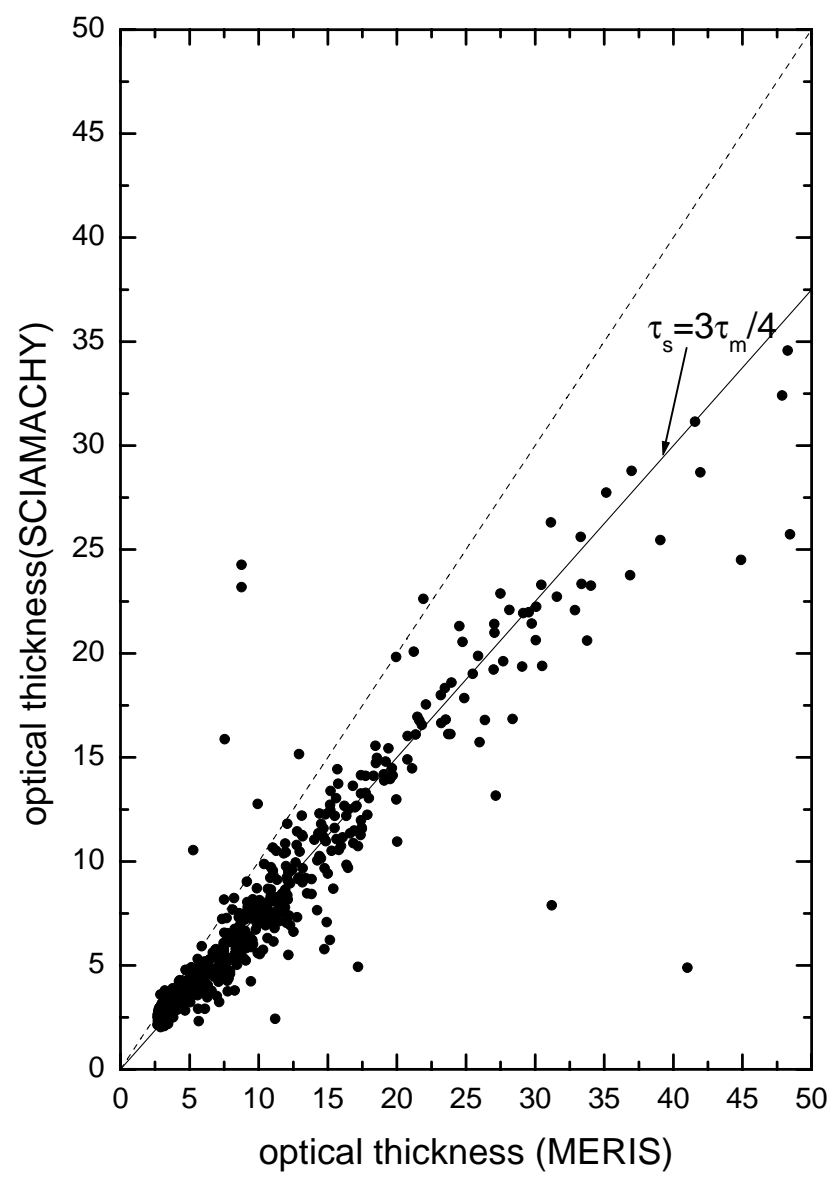

Fig. 6. Scatter plot of the SCIAMACHY-retrieved cloud optical thickness versus that of MERIS-retrieved at the wavelength $442 \mathrm{~nm}$.

Convenient expressions for the functions $K(\mu), R_{\infty}$, and $g$ are given by Kokhanovsky et al. (2003). Note that we have approximately for the case studied: $K(\mu) K\left(\mu_{0}\right)=1, R_{\infty}=1$ and $g=0.85$. Then one obtains the following approximate equation:

$\tau=\frac{9 R}{1-R}$.

This means that the ratio $A$ of the SCIAMACHY derived optical thickness $\tau_{s}$ to the MERIS derived optical thickness $\tau_{m}$ is given by the following expression:

$A=\frac{1-R_{m}}{C-R_{m}}$,

where $C=1.12$ as specified above and $R_{m}$ is the MERIS TOA reflection function. We present the dependence $A\left(R_{m}\right)$ in Fig. 5 .

It follows from Fig. 3 that $R_{m}<0.8$ in most cases. Then $A$ changes in the range $0.6-0.9$. So we can take as an average value: $A=0.75$ (see Fig. 5). Therefore, we should have as a consequence of $R_{m}=C R_{s}: \tau_{s}=0.75 \tau_{m}$. Here $R_{s}$ is the reflection function measured by SCIAMACHY. To check this 


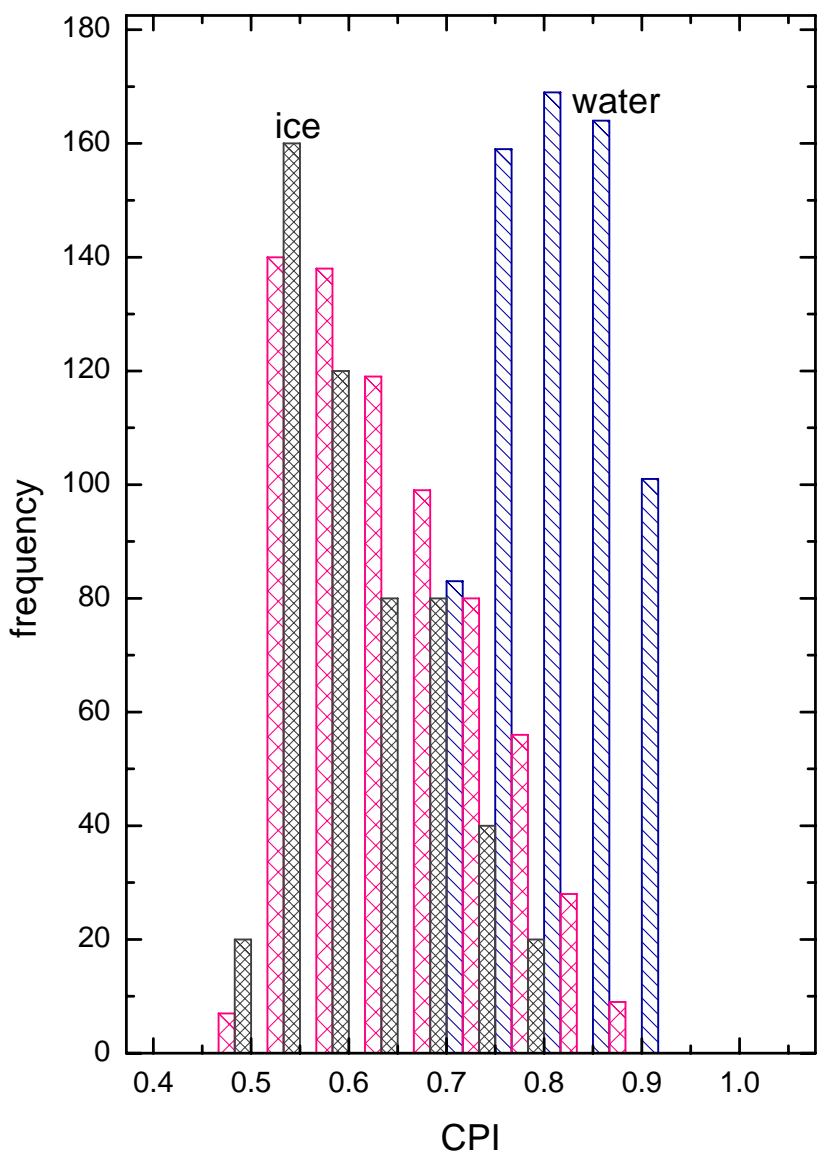

Fig. 7. The modeled CPI frequency distribution obtained using radiative transfer calculations.

we prepared a scatter plot similar to that shown in Fig. 3 but for the retrieved cloud optical thickness (see Eq. 1). Note that we did not use Level 2 MERIS cloud optical thickness. The results are given in Fig. 6. Our estimation, therefore, is confirmed. It means that if one does not account for the calibration coefficient ( $C=1.12$ ), then the retrieval gives lower values of the cloud optical thickness (by approximately $25 \%$ ) as compared to those obtained from MERIS measurements. This is a major conclusion of this work.

Similar biases must appear in the retrieved values of the liquid water path $w$ and the cloud droplet effective radius $a_{e f}$. However, it is difficult to correct them because the calibration coefficient is not spectrally neutral and the values of $w$ and $a_{e f}$ can be obtained only using SCIAMACHY measurements at $1500 \mathrm{~nm}$. Remind, that the largest wavelength of the MERIS is $900 \mathrm{~nm}$. So $C$ can not be found at larger wavelengths using MERIS.

\section{The cloud thermodynamic state}

The cloud thermodynamic state can not be estimated using MERIS data due to lack of infrared measurements.

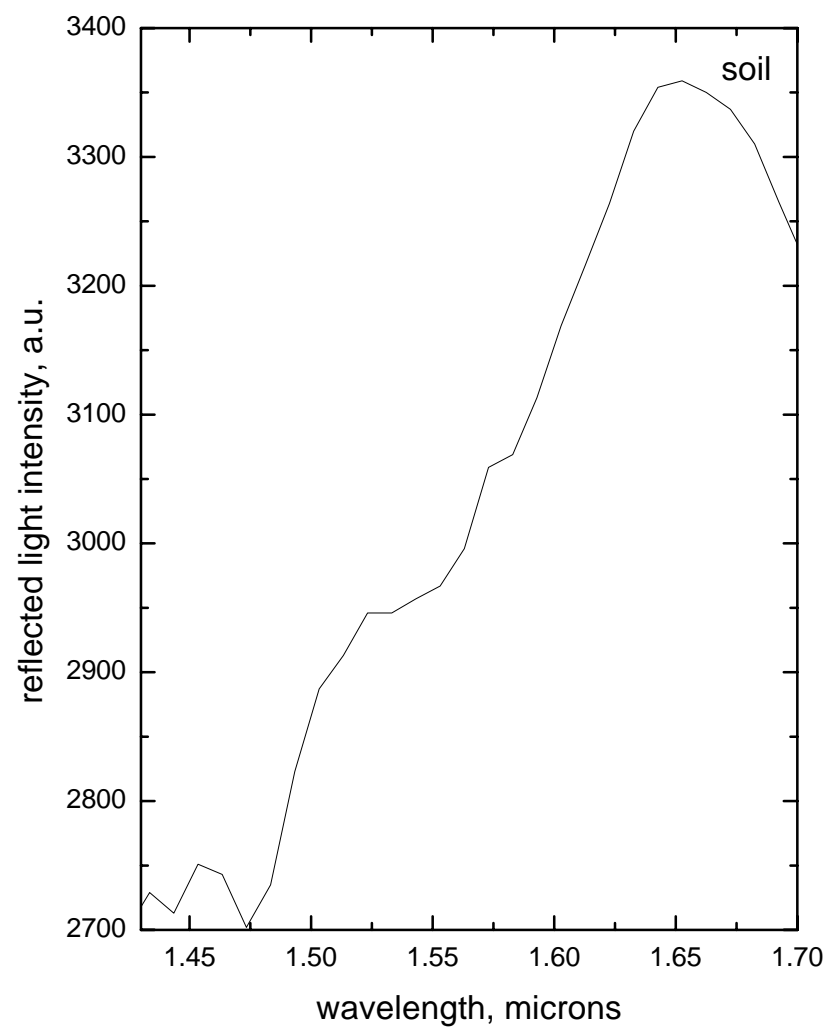

Fig. 8. The spectral reflectance of soil as measured by the Airborne Visible/Infrared Imaging Spectrometer (AVIRIS).

This can be done using SCIAMACHY, because it performs highly spectrally resolved measurements in the spectral region $1500-1700 \mathrm{~nm}$, where the spectral refractive index of ice differs considerably from that of water. This also brings about differences in the spectral reflectances detectable from a satellite. Let us introduce the so-called cloud phase index (CPI):

$\alpha=\frac{R(1550 \mathrm{~nm})}{R(1670 \mathrm{~nm})}$.

This index is similar but not identical to that proposed by Acarreta et al. (2004). The significance of this index is due to the fact that the imaginary part of the refractive index of ice considerably changes in the region $1550-1670 \mathrm{~nm}$. This is not the case for water (Acarreta et al., 2004). We find using radiative transfer calculations that the value of $\alpha$ is in the range $0.7-1.0$ for water clouds and it is in the range 0.5-0.7 for ice clouds (see Fig. 7). Calculations shown in Fig. 7 were performed using the modified asymptotic equations given by Kokhanovsky and Rozanov (2003) in the assumptions that both crystals and droplets have the spherical shape. It was assumed that the cloud optical thickness is varied in the range 5-30 for both water and ice clouds. The effective radius of water droplets was changed in the range 5-30 microns. For ice clouds we assumed two ranges of the 


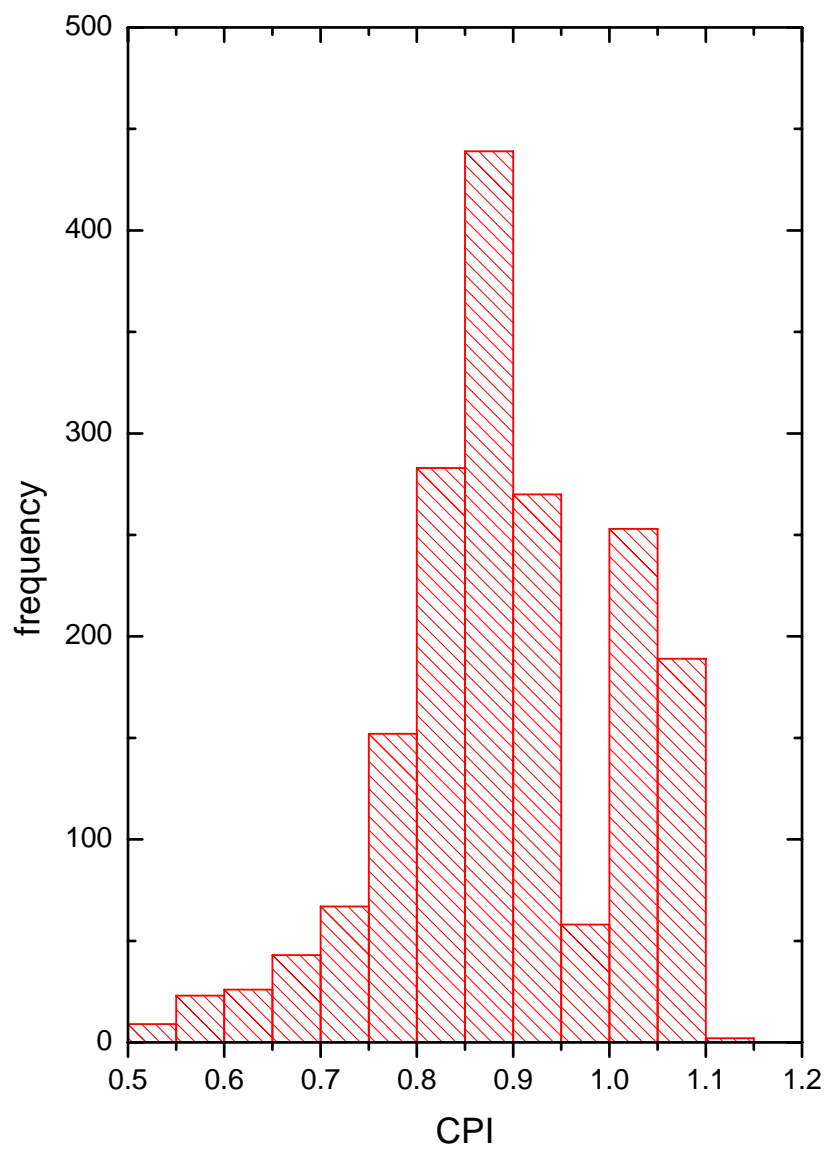

Fig. 9. The measured CPI frequency distribution obtained from SCIAMACHY infrared measurements.

effective radius change: 5-30 $\mu \mathrm{m}$ (red colour in Fig. 7) and $31-50 \mu \mathrm{m}$ (black colour in Fig. 7). The analysis shows that the increase of the size of particles increases the separation of both cloud types. Note that ice crystals have highly irregular shape and also the size is often in the range $100-500 \mu$. This will enhance differences even further. Calculations as shown in Fig. 7 correspond to the nadir observation and the solar zenith angle equal to 60 degrees. We found that the change of the illumination angle does not influence the positions of regions with characteristic values of CPI for water/ice cloud significantly. Therefore, CPI indeed can be used as an indicator of the cloud phase.

Obviously, we have for clear sky over a black surface: $R(1550 \mathrm{~nm})>R(1670 \mathrm{~nm})$, and, therefore, $\alpha>1$. Some highly reflecting soils could have values of $\alpha<1$ similar to water clouds (see Fig. 8). However, these pixels could be screened using information on the derived cloud top pressure, cloud optical thickness or both.

The probability distribution of CPI for the whole SCIAMACHY orbit analysed is shown in Fig. 9. There are similarities between Figs. 7 and 9. Interestingly, data with $\alpha>1$ appear in Fig. 9. These data are due to the clear pixels over wa-

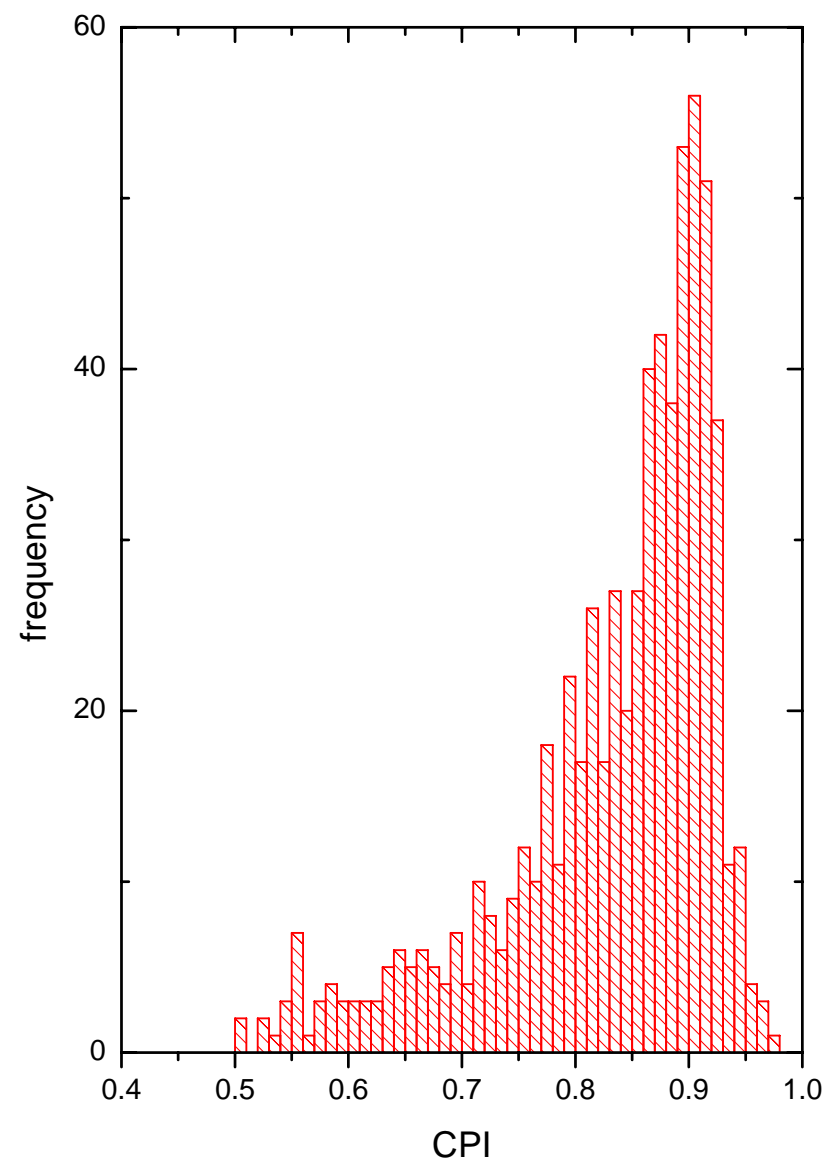

Fig. 10. The CPI measured by SCIAMACHY(similar to Fig. 9 but pixels with $R(442 \mathrm{~nm}) \leq 0.3$ are excluded).

ter. Note that not all pixels with $\alpha<1$ correspond to clouds. Some of them are due to soil spectral features clearly seen through the cloudless atmosphere, which is almost transparent at the wavelengths 1500 and $1670 \mathrm{~nm}$. Atmospheric scattering and gaseous absorption is low at these channels. We stress that the CPI could be also biased due to the partially cloudy pixels.

It follows that $\alpha=0.9$ for the soil spectrum given in Fig. 8. Therefore, we reprocessed data given in Fig. 9 to select only cloudy pixels. For this we used the condition: $R(442 \mathrm{~nm})>0.3$. The albedo of soil at this wavelength is below 0.1. Then the histogram has the form as shown in Fig. 10. One can conclude that with a rare exception, we deal with water clouds in the scene studied.

\section{The cloud top height}

The cloud top height can be found by analysing SCIAMACHY measurements in the oxygen A-band. One example of the SCIAMACHY spectrum together with the fit using the radiative transfer theory (Rozanov and Kokhanovsky, 2004) 


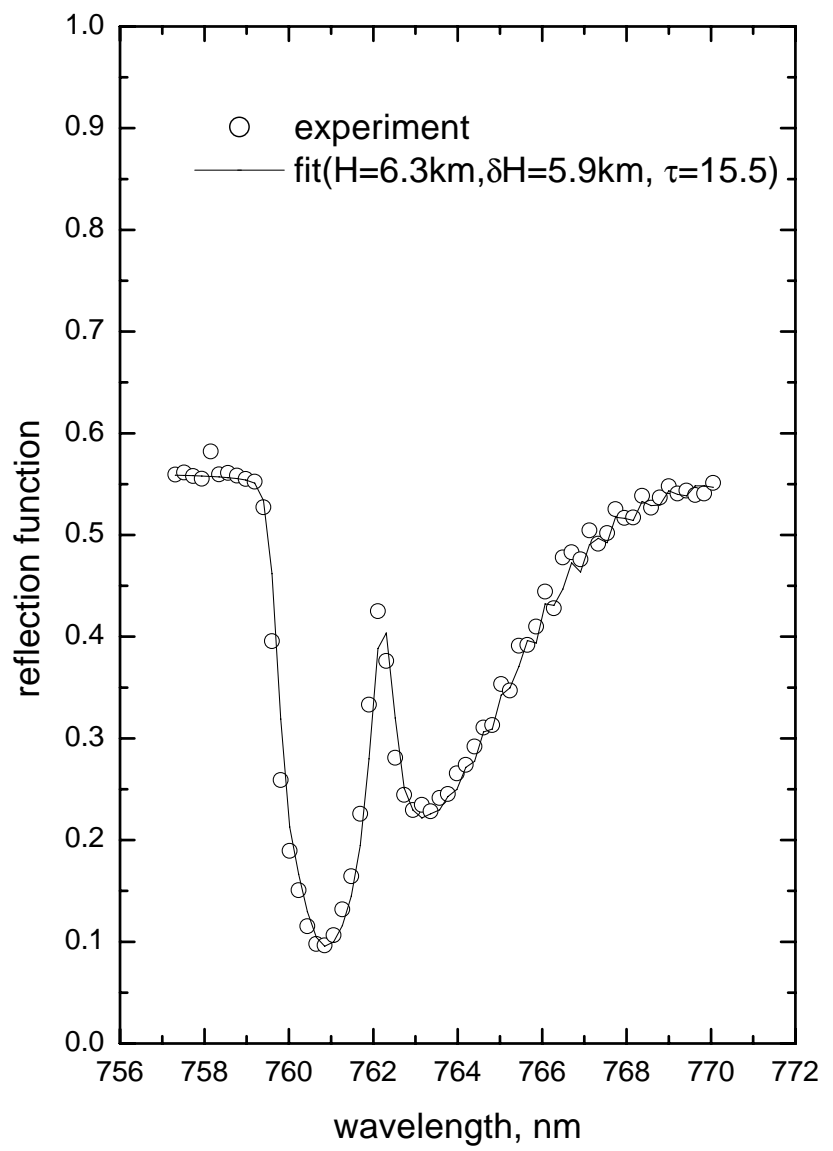

Fig. 11. The SCIAMACHY-measured oxygen A-band spectrum and the correspondent fit obtained using the radiative transfer theory.

is shown in Fig. 11. It follows that the experimental spectrum can be fitted using a cloud having the top height $H=6.3 \mathrm{~km}$, and the cloud geometrical thickness (CGT) equal to $5.9 \mathrm{~km}$ in the case studied. The optical thickness obtained from the fit is equal to 15.5. Note that the obtained value of $\tau$ could be biased due to the calibration errors as discussed above. Also the retrieved cloud geometrical thickness corresponds to the case of a single cloud layer. For multi-layered cloud systems, which often exist in the terrestrial atmosphere, the retrieved cloud geometrical thickness will differ from the total geometrical thickness of all layers. However, the cloud top height obtained with SCIAMACHY is least biased among all other cloud products derived due to the fact that the SACURA uses the relative reflection function for retrievals of $H$ as discussed by Rozanov and Kokhanovsky (2004). Then the issue of calibration is only of a minor importance. The same is true for CPI.

The cloud top height as retrieved for 4 selected states of SCIAMACHY is shown in Fig. 12. Clear sky pixels are represented by values of CTH equal or below zero. We see a high variability of cloud altitudes in the SCIAMACHY states

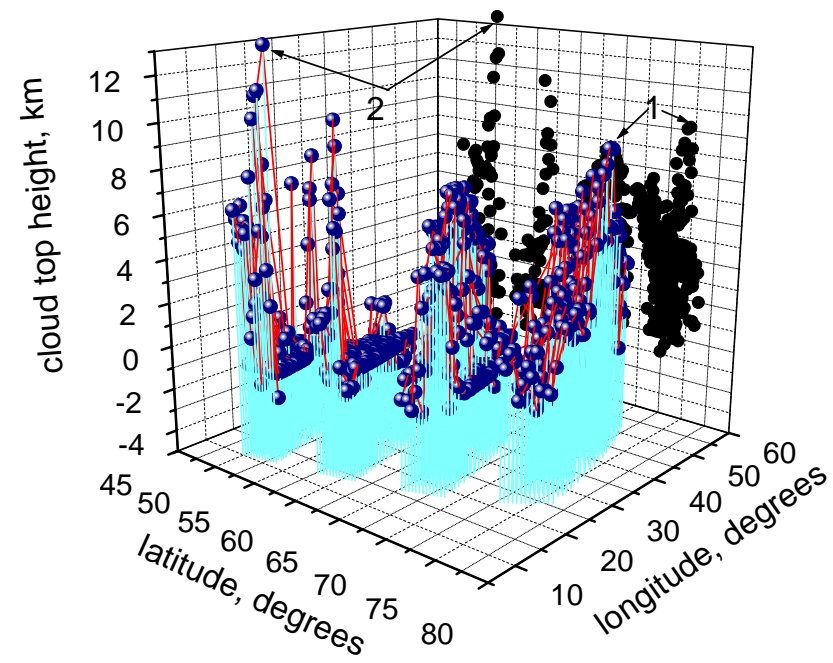

Fig. 12. The retrieved cloud top height for several SCIAMACHY states.

studied. Also the most northern state is characterized by quite high and extended cloudiness. This also points to the fact that crystals may exist in these clouds, which is confirmed by the spatial map of CPI (not shown here).

\section{Conclusions}

We show that the SACURA is capable to derive important cloud parameters using SCIAMACHY data such as the cloud optical thickness, the cloud top height, and the cloud thermodynamic state. The results of the retrievals may be biased due to the problems with the calibration of SCIAMACHY, if uncorrected operational level 1 data are used. In this paper we have used the Processor V3.51 L1 data and show that the SCIAMACHY reflectances at $442 \mathrm{~nm}$ are about 10 percent low as compared to MERIS measurements for the same ground scene.

The vicarious calibration of SCIAMACHY is an ongoing effort. Most probably, SCIAMACHY level 2 products will be reprocessed several times taking into account improved versions of the calibration constants derived from comparisons with other optical instruments in orbit, new theoretical calculations, lunar measurements, and re-analysis of pre-launched SCIAMACHY calibration data.

In conclusion, we underline that the SCIAMACHY provides an atmospheric research community with a wealth of new and important data reflecting global atmospheric conditions (including not only cloud properties but also trace gases abundances (Bovensmann et al., 2004) and also atmospheric aerosol characteristics (Hoyningen-Huene et al., 2006)). This is of a great importance for the atmospheric research in general and for the climate change problems in particular. One can find the cloud products as generated by SACURA on day-to-day basis at the website of the Institute 
of Remote Sensing (Bremen University) (http://www.iup. physik.uni-bremen.de/scia-arc). SACURA was selected as an official ESA cloud retrieval algorithm for SCIAMACHY. The operational retrievals using SACURA are performed by German Space Agency DLR.

Acknowledgements. This work has been funded by the DFG Project BU 6888/8-1 and also by BMBF via GSF/PT-UKF. We are grateful to the AVIRIS team for the spectrum shown in Fig. 8 and to S. Janz (NASA/GSFC) and TPD-TNO for providing the SCIAMACHY calibration data. MERIS and SCIAMACHY data were supplied by ESA. Discussions with P. Stammes and E. P. Zege are highly appreciated. We thank B. J. Kerridge and B. Latter for providing results of their comparisons of the top of atmosphere reflectance measured by AATSR with that obtained by SCIAMACHY.

Edited by: U. Platt

\section{References}

Acarreta, J. R., Stammes, P., and Knap, W. H.: First retrieval of cloud phase from SCIAMACHY spectra around $1.6 \mu \mathrm{m}$, Atmos. Res., 72, 89-105, 2004.

Acarreta, J. R. and Stammes, P.: Calibration comparison between SCIAMACHY and MERIS onboard ENVISAT, IEEE Geosci. Rem. Sens. Let., 2, 31-35, 2005.

Bovensmann, H., Burrows, J. P., Buchwitz, M., Frerick, J., Noël, S., and Rozanov, V. V.: SCIAMACHY: Mission objectives and measurement method, J. Atmos. Sci., 56, 127-150, 1999.
Bovensmann, H., Buchwitz, M., Frerick, J., et al.: SCIAMACHY on ENVISAT: In-flight optical performance and first results, in: Remote Sensing of Clouds and the Atmosphere, edited by: Schäfer, K. P., Comeron, A., Carleer, M. R., and Picard, R. H., SPIE Proc., 5235, 160-173, 2004.

Crutzen , P. J. and Ramanathan, V. J. (Eds.): Clouds, Chemistry, and Climate, Springer, Berlin, 1996.

Kokhanovsky, A. A. and Rozanov, V. V.: The reflection function of optically thick weakly absorbing turbid layers: a simple approximation, J. Quant. Spectr. Rad. Transfer, 77, 165-175, 2003.

Kokhanovsky, A. A. and Rozanov, V. V.: The physical parameterization of the top-of-atmosphere reflection function for a cloudy atmosphere-underlying surface system: the oxygen A-band case study, J. Quant. Spectr. Rad. Transfer, 85, 35-55, 2004.

Kokhanovsky, A. A., Rozanov, V. V., Nauss, T., Reudenbach, C., Daniel, J. S., Miller, H. L., and Burrows, J. P.: The semianalytical cloud retrieval algorithm for SCIAMACHY I. The validation, Atmos. Chem. Phys., 6, 1905-1911, 2006, http://www.atmos-chem-phys.net/6/1905/2006/.

Kokhanovsky, A. A., Rozanov, V. V., Zege, E. P., Bovensmann, H., and Burrows, J. P.: A semianalytical cloud retrieval algorithm using backscattered radiation in $0.4-2.4 \mu \mathrm{m}$ spectral region, J. Geophys. Res., 108(D1), 4008, doi:10.1029/2001JD001543, 2003.

Raschke, E. (Ed.): Radiation and water in the Climate System, Springer, Berlin, 1996.

Rozanov, V. V. and Kokhanovsky, A. A.: Semianalytical cloud retrieval algorithm as applied to the cloud top altitude and the cloud geometrical thickness determination from top-of-atmosphere reflectance measurements in the oxygen A band, J. Geophys. Res., 109, D05202, doi:10.1029/2003JD004104, 2004.

von Hoyningen-Huene, W., Kokhanovsky, A. A., Wuttke, M. W., et al.: Validation of SCIAMACHY top-of-atmosphere reflectance for aerosol remote sensing using MERIS L1 data, Atmos. Chem. Phys. Discuss., 6, 673-699, 2006,

http://www.atmos-chem-phys-discuss.net/6/673/2006/. 